\title{
ПРОФЕССИОНАЛЬНАЯ ПОДГОТОВКА
}

УДК 37.015.324.2

DOI 10.23951/1609-624X-2018-7-136-141

\section{ФОРМИРОВАНИЕ ГОТОВНОСТИ К ОСВОЕНИЮ ПРОФЕССИИ У СТУДЕНТОВ НА НАЧАЛЬНОМ ЭТАПЕ ОБУЧЕНИЯ}

\section{Е. В. Балганова}

\begin{abstract}
Сибирский институт управления, филиал Российской академии народного хозяйства и государственной службы при Президенте Российской Федераџии, Новосибирск
\end{abstract}

Рассматриваются результаты опытно-экспериментальной работы по формированию готовности к освоению профессии у студентов на начальном этапе обучения. Ранее полученные в исследовании результаты позволили сделать вывод о низкой информированности первокурсников о специфике, сущности и содержании выбранной профессии, недостаточной осознанности, направленности и выраженности мотивов в ее освоении, слабой сформированности ряда требуемых профессионально важных качеств. Это привело к необходимости разработки и внедрения комплекса педагогических средств: программы учебного курса «Введение в профессиональную деятельность», учебного пособия и других методических средств. Приведены результаты экспериментальной апробации учебного курса.

Ключевые слова: образовательный процесс, формирование готовности к освоению профессии, пропедевтический учебный курс, методическое обеспечение, оценка результатов.

В настоящее время задача формирования готовности к освоению профессии у студентов в процессе обучения является важнейшей в практике образовательной деятельности вуза. Это обусловлено тем, что во время обучения закладываются основы компетентности и формируются существенные предпосылки к эффективной профессиональной деятельности.

В научных исследованиях А. А. Вагаповой, Е. Е. Бочаровой, Е. А. Климова, Ю. П. Поваренкова, Н. С. Пряжникова, А. А. Реана, Е. Н. Тулебаевой, Л. Б. Шнейдера и др. отмечено, что важным условием качества обучения является начальная подготовленность студентов к освоению профессии, которая определяется ценностным отношением к выбранной профессии и вытекает из представлений о ее содержании, личной и социальной значимости, наличии необходимых качеств [1-7]. Как показывает педагогическая практика, первокурсники не всегда хорошо осведомлены о специфике и содержании приобретаемой профессии, что отражается на их отношении к учебной и будущей профессиональной деятельности в целом. Кроме того, у многих из них, выбравших профессию под влиянием случайных факторов, не сформированы предпосылки к ее освоению. Данные выводы подтверждает проведенное авторами исследование по оценке готовности студентов - будущих бакалавров менеджмента к освоению профессии [8, c. 1277]. Это приводит к необходимости корректировки на 1-м курсе представления студентов о бу- дущей профессии и целенаправленного формирования необходимых для ее освоения характеристик.

Одним из способов решения данной проблемы, на взгляд авторов, является внедрение в программу подготовки бакалавров по направлению «Управление персоналом» специально разработанного комплекса педагогических средств, включающего учебный курс «Введение в профессиональную деятельность», формы и методы организации образовательного процесса по учебному курсу и его методическое обеспечение. Данный курс имеет пропедевтическую направленность. Основной целью курса является формирование у бакалавров первоначальной ориентировки в пространстве будущей профессии и мотивации к ее освоению. В качестве частной цели курса выступает формирование представлений об организации и содержании учебной деятельности студента вуза.

Исходя из целей, в учебном курсе последовательно решаются следующие задачи:

- обеспечение первоначальной адаптации студентов к условиям обучения в вузе и развитие мотивации к освоению образовательной программы;

- формирование у студентов системных представлений о сущности и содержании избранной профессии, понимание требований к личностным и профессиональным компетенциям специалиста, значимости развития профессионально важных качеств; 
- формирование у студентов установки на субъектную позицию в процессе профессионального становления.

При проектировании образовательного процесса по учебному курсу применялся алгоритм действий, включающий в себя основные инвариантные компоненты: декомпозицию учебных целей и связанных с ними планируемых результатов обучения, отбор и структурирование содержания, определение форм и методов обучения, способов оценивания результатов освоения курса в ходе и по окончании изучения по критериям выполнения соответствующих диагностических заданий и проработка системообразующей связи между компонентами. Такой подход дает возможность обеспечения структурной, содержательной и методической целостности курса, взаимосвязи с другими учебными курсами и в целом направленности на развитие предпосылок к формированию профессиональных компетенций.

Учебные цели курса и соответствующие им результаты обучения сформулированы по трем уровням освоения учебного материала с помощью глаголов-дескрипторов «иметь представления»; «знать»; «уметь» (табл. 1).

В связи с этим учебный материал курса структурирован по трем блокам, каждый из которых включает в себя соответствующие темы. Так, со- держание адаптационного блока раскрывается посредством включенных в него таких тем, как: «Сибирский институт управления: общая характеристика и история развития»; «Основы организации учебного процесса в вузе». Данный блок предназначен для обеспечения первоначальной адаптации студентов к условиям учебной деятельности. Содержание профессионального блока определяется темами: «Эволюция и модернизация образовательных и профессиональных стандартов в сфере управления персоналом»; «Профессиональная деятельность специалистов по работе с персоналом организации», - способствующими формированию у бакалавров первоначальной ориентировки в пространстве будущей профессии, мотивации к освоению профессиональных курсов. Для формирования осознанного понимания требований к компетенциям специалиста в образовательный процесс по учебному курсу включен личностный блок, который содержательно обогащен следующей тематикой: «Профессионально важные качества специалистов в сфере управления персоналом» и «Развитие профессионализма».

Поскольку данный курс изучается в первом семестре, то его освоение опирается на результаты обучения по программам среднего общего образования (среднего профессионального образования).

Таблица 1

Цели и планируемые результаты освоения учебного курса

\begin{tabular}{|c|c|}
\hline Уровень & Содержание учебного материала \\
\hline Иметь представления & Об истории становления и развития вуза \\
\hline \multirow[t]{8}{*}{ Знать } & $\begin{array}{c}\text { О правовом статусе студента, правовых основах взаимодействия с другими участниками образова- } \\
\text { тельного процесса в вузе }\end{array}$ \\
\hline & О формах организации учебно-воспитательного процесса в вузе \\
\hline & Сущность и содержание основных компонентов культуры учебного труда \\
\hline & Основные приемы планирования учебной деятельности \\
\hline & $\begin{array}{c}\text { Структуру и содержание образовательного и профессионального стандартов в области управления } \\
\text { персоналом }\end{array}$ \\
\hline & $\begin{array}{c}\text { Сферу деятельности, профессиональные задачи и специализированные функции специалистов по } \\
\text { работе с персоналом }\end{array}$ \\
\hline & $\begin{array}{l}\text { Требования, предъявляемые профессией к знаниям, умениям, навыкам и профессионально } \\
\text { важным качествам специалиста }\end{array}$ \\
\hline & Критерии, уровни, этапы становления профессионализма \\
\hline \multirow[t]{6}{*}{ Уметь } & $\begin{array}{c}\text { Использовать образовательные и профессиональные стандарты как ориентиры собственной } \\
\text { образовательной деятельности }\end{array}$ \\
\hline & Планировать учебную деятельность в соответствии с целями \\
\hline & $\begin{array}{c}\text { Анализировать результаты собственной учебной деятельности на разных этапах образовательного } \\
\text { процесса }\end{array}$ \\
\hline & $\begin{array}{c}\text { Формулировать профессиональные задачи в соответствии с функциями должностей в сфере } \\
\text { управления персоналом }\end{array}$ \\
\hline & Оценивать сформированность собственных профессионально важных качеств \\
\hline & Давать характеристику специалиста-профессионала разного уровня \\
\hline
\end{tabular}


В свою очередь, освоение курса становится пререквизитом для ряда дисциплин со взаимосвязанными учебными целями и общностью понятийно-категориального аппарата: «Основы управления персоналом», «Управление саморазвитием» и «Акмеология».

С целью методического обеспечения освоения дисциплины разработан учебно-тематический план, отражающий блок, цели и планируемые результаты обучения, темы занятий и учебную деятельность обучающихся (табл. 2).

Разработка планируемых результатов обучения и форм учебной деятельности обучающихся при изучении курса обеспечивает возможность определения методов, видов контроля и оценки приобретенных знаний и умений.

Для эффективного обучения по учебному курсу применяются методы, обеспечивающие активность мыслительной и практической деятельности обучающихся в процессе освоения учебного материала: деловые («Секрет Джовани», «Стандарт профессионально важных качеств менеджера по персоналу», «Архипелаг ценностей в профессии») и ролевые («Донорское сердце») игры; анализ конкретных ситуаций («Социальные и профессиональные роли менеджера по персоналу», «Один день работы менеджера»), кейс-задачи («Профессия как образ жизни» и др.).

Результаты освоения курса обучающимися определяются по балльно-рейтинговой системе оценки учебной деятельности (БРС), суть которой состоит в контроле и оценке знаний, умений по установленным критериям, в качестве которых вы-

ступают планируемые результаты обучения, которые обучающийся должен проявить при выполнении определенных заданий. Для практической реализации БРС разработана информационная карта как своего рода путеводитель для студентов по организации учебной деятельности при изучении курса. Информационная карта содержит учебнотематический план изучения дисциплины, задания для самостоятельной работы студентов, критерии оценки и их весовые коэффициенты по каждому критерию, формы текущего и рубежного контроля. Кроме того, в ней содержится информация о сроках изучения учебного материала и контроля.

С целью учебно-методического обеспечения учебного курса разработано учебное пособие, в котором раскрывается сущность и содержание профессии «менеджер по персоналу». Структура пособия отвечает дидактическим и методическим требованиям, включает в себя необходимые части: основную (материал для лекций); пояснительную (раскрытие ключевых терминов, которые выделены курсивом там, где они встречаются впервые, а также определение основных понятий); методическую (задания репродуктивного и творческого, вопросы для самопроверки качества освоения учебного материала и литература для дополнительного изучения) [9]. Это позволяет студентам глубоко усваивать содержание курса, понимать сущность и социальную значимость своей будущей профессии. Следует отметить, что учебное издание имеет гриф «Рекомендовано советом Учебно-методического объединения по образованию в области менеджмента в качестве учебного пособия для сту-

Таблица 2

Учебно-тематический план курса «Введение в профессиональную деятельность» (извлечение)

\begin{tabular}{|c|c|c|c|}
\hline Блок & Планируемые результаты обучения & Темы занятий & Содержание учебной деятельности обучаюшихся \\
\hline 蓶 & \begin{tabular}{|} 
Знание сущности и содержание основных \\
компонентов культуры учебного труда. \\
Знание основных приемов планирования \\
учебной деятельности. \\
Умение планировать учебную деятельность \\
в соответствии с целями
\end{tabular} & $\begin{array}{l}\text { Основы органи- } \\
\text { зации учебного } \\
\text { процесса в вузе }\end{array}$ & $\begin{array}{c}\text { Составляют понятийную карту по исходным } \\
\text { понятиям. } \\
\text { Разрабатывают модели культуры учебного труда и } \\
\text { требований к личностным качествам студента. } \\
\text { Представляют доклады о приемах планирования } \\
\text { учебной деятельности. } \\
\text { Разрабатывают план по выполнению заданий }\end{array}$ \\
\hline 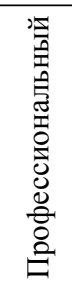 & $\begin{array}{c}\text { Знание структуры и содержание образова- } \\
\text { тельного и профессионального стандартов в } \\
\text { области управления персоналом. } \\
\text { Умение использовать образовательные и } \\
\text { профессиональные стандарты как ориенти- } \\
\text { ры собственной образовательной деятель- } \\
\text { ности }\end{array}$ & $\begin{array}{c}\text { Эволюция и } \\
\text { модернизация } \\
\text { образовательных и } \\
\text { профессиональных } \\
\text { стандартов в сфере } \\
\text { управления } \\
\text { персоналом }\end{array}$ & $\begin{array}{c}\text { Знакомятся с содержанием образовательных и } \\
\text { профессиональных стандартов и письменно } \\
\text { отвечают на вопросы. } \\
\text { Представляют общую характеристику профессии } \\
\text { на основе анализа ФГОС ВО и ПС }\end{array}$ \\
\hline 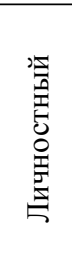 & \begin{tabular}{|c|} 
Знание требований, предъявляемых \\
профессией к знаниям, умениям, навыкам и \\
профессионально важным качествам \\
специалиста. \\
Умение оценивать сформированность \\
собственных профессионально важных \\
качеств
\end{tabular} & $\begin{array}{c}\text { Профессионально } \\
\text { важные качества } \\
\text { специалистов в } \\
\text { сфере управления } \\
\text { персоналом }\end{array}$ & $\begin{array}{c}\text { Определяют основные ПІВК менеджера по } \\
\text { персоналу на основе схемы А. В. Карпова. } \\
\text { Осуществляют подбор методов диагностики и } \\
\text { интерпретируют результаты диагностики. } \\
\text { Определяют пути совершенствования ПВК }\end{array}$ \\
\hline
\end{tabular}


дентов высших учебных заведений, обучающихся по направлению подготовки 38.03.03 „Управление персоналом“ (квалификация (степень „бакалавр“)» (протокол № 52/28-2 от 31 марта 2014 г.). Кроме того, в 2014 г. учебное пособие участвовало во всероссийском конкурсе «Лучшая научно-методическая разработка по управлению персоналом», его авторы награждены дипломом III степени.

Таким образом, разработанный учебный курс «Введение в профессиональную деятельность» в полной мере позволяет обеспечить пропедевтику для осознанного вхождения в будущую профессию, создания основы для изучения профессиональных курсов и развития предпосылок к формированию профессиональных компетенций у бакалавров.

Апробация учебного курса проводилось с 2012 по 2016 учебный год. В исследовании приняли участие 258 студентов первого курса очного отделения, из них 130 человек экспериментальной группы (ЭГ), обучающихся в Сибирском институте управления РАНХиГС (г. Новосибирск) (126 девушек, 4 юношей, средний возраст - 19 лет), и 128 человек контрольной группы (КГ), обучающихся во Владивостокском государственном университете экономики и сервиса (122 девушки, 6 юношей, средний возраст - 19 лет).

С целью выявления уровня сформированности готовности к освоению профессии и развития предпосылок к формированию профессиональных компетенций у студентов проведена диагностика по окончании изучения учебного курса.

Для оценки результатов обучения применялся входной контроль по дисциплине, которая изучается после курса «Введение в профессиональную деятельность», - «Основы управления персоналом». Входной контроль в начале изучения следующей дисциплины выбран в качестве способа диагностики в связи с тем, что он является традиционным и действенным способом проверки остаточных знаний по изученной ранее взаимосвязанной дисциплине, а также выявления готовности обучающихся к более глубокому освоению учебного материала, наличия пробелов в знаниях и др.

Входной контроль проводился в форме тестирования. Обучающимся предлагалось выполнить три блока тестовых заданий по 10 в каждом. В первый блок были включены задания, направленные на проверку сформированности знаний ключевых понятий и терминов профессиональной деятельности. Второй блок заданий ориентирован на проверку сформированности у студентов первоначальных системно-организованных знаний о сущности, направлениях и содержании будущей профессиональной деятельности. Третий блок направлен на оценку знаний нормативных квалификационных требований профессиональной деятельности.
Оценка результатов тестирования основывалась на подходе В. П. Беспалько, сущность которого заключается в определении коэффициента успешности выполнения заданий, шкалу соответствия коэффициентов успешности и уровней усвоения знаний и умений [10]. Под успешностью авторами понимается результативность (полнота) и качество (правильность) решения специальных заданий.

Расчет коэффициента проводился по формуле:

$$
K_{\mathrm{y}}=n \div m \text {, }
$$

где $K_{\mathrm{y}}$ - коэффициент успешности; $n$ - количество выполненных заданий студентом; $m$ - общее количество заданий, которые должен выполнить студент (эталон).

Для определения общего коэффициента успешности $K_{\text {у общ }}$ введены весовые коэффициенты, которые установлены исходя из сложности заданий: для первого типа заданий $K_{\mathrm{y} 1}-0,25$, для второго $K_{\text {у2 }}-0,30$, третьего $K_{\text {у3 }}-0,45$.

Шкала соответствия коэффициентов успешности и уровней усвоения знаний и умений: ниже 0,5 - низкий уровень; от 0,5 до 0,69 - минимальный уровень; от 0,7 до 0,84 - достаточный уровень; от 0,85 до 1,0 - высокий уровень.

Кроме того, дополнительно применялось анкетирование. Разработанная анкета включала 12 вопросов, направленных на выявление мнения студентов в отношении мотивации выбора профессии, понимания ее личностной и социальной значимости и осознания себя как субъекта ее выбора и освоения.

Анализ результатов тестирования по блокам показал, что практически все обучающиеся ЭГ успешно справились с тестовыми заданиями первого блока, в котором необходимо было воспроизвести и определить содержание понятий и терминов профессиональной деятельности (средний коэффициент успешности составляет 0,76), студенты КГ с данными заданиями справились несколько хуже (средний коэффициент успешности - 0,69). Результаты выполнения заданий второго блока также показали, что в экспериментальной группе знания о сущности, направлениях и содержании профессиональной деятельности, а также умения соотносить должности с трудовыми функциями и категориальной принадлежностью сформированы значительно лучше, чем у студентов контрольной группы (средние коэффициенты успешности $-0,74$ и 0,63 соответственно). Оценка знаний по тестовым заданиям третьего блока выявила еще большие расхождения между обучающимися (средние коэффициенты успешности - 0,71 и 0,55 соответственно).

По результатам анкетирования установлено, что большинство опрошенных ЭГ (86 \%) сделали 
правильный выбор профессии и, более того, рекомендовали бы получать образование по этой профессии друзьям и знакомым. Только 14 \% студентов не уверены в выборе, однако учиться этой профессии, по их словам, им нравится. В КГ результаты отличаются: 67 \% студентов также подтвердили правильность сделанного выбора, 29 \% не определились, а $4 \%$ считают, что ошиблись с выбором профессии. Также значительно разнятся данные о планировании по окончании обучения работать по избранной профессии: доля студентов, сомневающихся в трудоустройстве по специальности, в контрольной группе составляет $29 \%$, а в экспериментальной - $3 \%$.

При оценке собственных знаний об избранной профессиональной деятельности студенты экспериментальной группы были достаточно объективны, так как более половины из них считали, что получили общие представления о ее содержании $(64 \%)$, треть - что их представления носят неполный и неточный характер (26\%) и $10 \%$ оценили свои знания как полные и точные. При этом в меньшей степени обучающиеся были осведомлены об условиях профессиональной деятельности (соответственно 53 и $31 \%$ респондентов, выбравших данный ответ).

Обращает на себя внимание тот факт, что в экспериментальной группе не оказалось респонден- тов, затруднившихся с выбором ответа, тогда как в контрольной группе таких студентов оказалось больше половины $(57$ \%). Менее всего студенты контрольной группы оказались информированы о содержании и условиях профессиональной деятельности, требованиях к специалистам.

Рефлексия процесса обучения с точки зрения интереса и трудности выражена у испытуемых обеих групп относительно в одинаковой степени: с вариантом «учиться не интересно» не согласился никто, в то время как большая часть (78 \% в ЭК и $75 \%$ в КГ) согласилась, что учиться «интересно, но трудно». Тем не менее около половины испытуемых обеих групп (46 \% в ЭГ и $42 \%$ в КГ) думают об обучении в магистратуре в дальнейшем.

Итак, обобщение результатов диагностики готовности к освоению профессии и развития предпосылок к формированию профессиональных компетенций у студентов показало, что целенаправленное обучение по пропедевтическому курсу «Введение в профессиональную деятельность» на начальном этапе обучения способствует тому, что у обучающихся на основе системных знаний о сущности, направлениях и содержании будущей профессии формируется осознанное отношение к ней и мотивация на овладение ею, понимание ее значимости, а также предпосылки к развитию профессионально важных качеств.

\section{Список литературы}

1. Вагапова А. В., Бочарова Е. Е. Психологическое сопровождение профессионального становления личности студента в условиях вузовского образования // Психология образования в XXI веке. Волгоград: Перемена, 2011. C. 168-172. URL: http://psyjournals.ru/education21/ issue/54390_full.shtml (дата обращения: 11.02.2018).

2. Климов Е. А. Психология профессионального самоопределения: учеб. пособие. М.: Академия, 2004. 304 с.

3. Поваренков Ю. П. Психологическое содержание профессионального становления человека. М.: Ун-т рос. акад. образования, 2002. $160 \mathrm{c}$.

4. Пряжников Н. С. Профориентация в системе управления человеческими ресурсами: метод. пособие. М.: Академия, 2014. 286 с.

5. Реан А. А. Психология и психодиагностика личности: теория, методы исслед., практикум. СПб.: Прайм-Еврознак, 2008. 255 с.

6. Тулебаева Е. Н., Мерсиянова А. П. Готовность выпускников школ к самостоятельной работе как определяющему виду учебной деятельности в вузе // Вестн. Казахстанско-Американского свободн. ун-та. Вып.: «Образовательные технологии». 2007. № 1. С. $162-169$.

7. Шнейдер Л. Б. Профессиональная идентичность: опыт теоретико-экспериментального исследования. М.: Прометей, 2004. $334 \mathrm{c}$.

8. Балганова Е. В., Богдан Н. Н. Оценка готовности бакалавров менеджмента к освоению профрессии в сфере управления персоналом // Профессиональное образование в современном мире. 2017. Т. 7, № 3. С. 1274-1278.

9. Балганова Е. В., Богдан Н. Н. Введение в профессиональную деятельность: учеб. пособие для студентов всех форм и технологий обучения по направлению подгот. 080400.62 «Упр. персоналом» (квалификация (степень) «бакалавр») / Рос. акад. нар. хоз-ва и гос. службы при Президенте РФ, Сиб. ин-т упр. Новосибирск: Изд-во СибАГС, 2013. 127 с.

10. Беспалько В. П. Слагаемые педагогической технологии. М.: Педагогика, 1989. 192 с.

Балганова Елена Владимировна, старший преподаватель, Сибирский институт управления - филиал РАНХиГС (ул. Нижегородская, 6, Новосибирск, Россия, 630112).

E-mail: elena-balganova@mail.ru 
DOI 10.23951/1609-624X-2018-7-136-141

\section{FORMATION OF READINESS TO THE PROFESSION DEVELOPMENT AMONG STUDENTS AT THE INITIAL TRAINING STAGE}

\section{E. V. Balganova}

Siberian Institute of Management, branch of Russian Presidential Academy of National Economy and State Service under the President of the Russian Federation, Novosibirsk, Russian Federation

The results of experimental work on approbation of pedagogical support for the formation of readiness of bachelors of management for profession development are considered. The results obtained earlier in the course of the study made it possible to conclude that the first-year students participating in the study who chose the direction of training "Human Resources Management" have low awareness of the specifics, nature and content of the professional work of personnel specialists, orientation and expression of motives, formation of professionally important qualities. This determines the necessity to strengthen the orientation on the formation of personal readiness to master the profession from the first days of study at the university. In this regard, a set of pedagogical means has been developed and implemented, namely: the program of the training course "Introduction to Professional Activitiy", a training manual and other methodical means. The content of the training course was realized according to a specific algorithm, including the decomposition of learning objectives and related with them planned results of training, selection and structuring of content, determination of methods for assessing the results of course mastering during and at the end of the study according to criteria and indicators for the implementation of relevant diagnostic tasks. This approach made it possible to ensure the structural, substantive and methodological integrity of the course, the relationship with other training courses and, in general, to pay attention to improving the level of readiness of bachelors in management to master professional competencies at the initial stage of training. The results of approbation confirm the hypothesis put forward by us on the need to include this course in the professional training of bachelors of management to ensure its effectiveness.

Key words: educational process, formation of readiness for the development of the profession, propaedeutic training course, methodological support, evaluation of the results.

\section{References}

1. Vagapova A. A., Bocharova E. E. Psikhologicheskoye soprovozhdeniye professional'nogo stanovleniya lichnosti studenta v usloviyakh vuzovskogo obrazovaniya [Psychological support of professional formation of personality of a student in conditions of University education]. Psikhologiya obrazovaniya v XXI veke [Psychology of education in the XXI century]. Volgograd, 2011. Pp. 168-172 (in Russian). URL: http:// psyjournals.ru/education21/issue/54390_full.shtml. (accessed 11 February 2018).

2. Klimov E. A. Psikhologiya professional'nogo samoopredeleniya: ucheb. posobiye [Psychology of professional self-determination: textbook]. Moscow, Akademiya Publ., 2004. 304 p. (in Russian).

3. Povarenkov Yu. P. Psikhologicheskoye soderzhaniye professional'nogo stanovleniya cheloveka [Psychological content of professional formation of a person]. Moscow, URAE Publ., 2002. 160 p. (in Russian).

4. Pryazhnikov N. S. Proforiyentatsiya v sisteme upravleniya chelovecheskimi resursami: metodicheskoye posobiye [Vocational guidance in the system of human resources management: study guide]. Moscow, Akademiya Publ., 2014. 286 p. (in Russian).

5. Rean A. A. Psikhologiya i psikhodiagnostika lichnosti: teoriya, metody issled., praktikum [Psychology and psycho-diagnostics of personality: theory, research methods, practical work]. Saint Petersburg, Praym-Evroznak Publ, 2008. 255 p. (in Russian).

6. Tulebaeva E. N., Mersiyanova A. P. Gotovnost' vypusknikov shkol k samostoyatel'noy rabote kak opredelyayushchemu vidu uchebnoy deyatel'nosti v vuze [Readiness of graduates of schools for independent work as to the defining type of educational activity in higher education institution]. Vestnik Kazakhstansko-Amerikanskogo Svobodnogo Universiteta. Vypusk: Obrazovatel'nye tekhnologii - KAFU Academic Journal. Issue: Educational technologies, 2007, no. 1, pp. 162-169 (in Russian).

7. Shneyder L. B. Professional'naya identichnost': opyt teoretiko-eksperimental'nogo issledovaniya [Professional identity: the experience of theoretical and experimental studies]. Moscow, Prometey Publ., 2004. 334 p. (in Russian).

8. Balganova E. V., Bogdan N. N. Otsenka gotovnosti bakalavrov menedzhmenta k osvoeniyu professii v sfere upravleniya personalom [Assessment of readiness of bachelors of management to the development of the profession in the field of personnel management]. Professional'noye obrazovaniye v sovremennom mire - Professional education in the modern world, 2017, vol. 7, no. 3, pp. 1274-1278 (in Russian).

9. Balganova E. V., Bogdan N. N. Vvedeniye v professional'nuyu deyatel'nost': ucheb. posobiye dlya studentov vsekh form i tekhnologiy obucheniya po napravleniyu podgot. 080400.62 "Upr. Personalom" (kvalifikatsiya (stepen) "bakalavr") [Introduction to professional activity: manual for students of all forms and technologies of training in the direction of training. 080400.62 "Personnel Management" (qualification (degree)" "bachelor")]. Novosibirsk, SibAGS Publ., 2013. 127 p. (in Russian).

10. Bespal'ko V. P. Slagayemyye pedagogicheskoy tekhnologii [Components of educational technology]. Moscow, Pedagogika Publ., 1989. 192 p. (in Russian).

Belganova E. V., Siberian Institute of Management, branch of Russian Presidential Academy of National Economy and State Service under the President of the Russian Federation (ul. Nizhegorodskaya, 6, Novosibirsk, Russian Federation, 630112).

E-mail: elena-balganova@mail.ru 